\title{
LETTER TO THE EDITOR (August 24, 2017) CONCERNING THE PAPER "OCCUPATIONAL EXPOSURE TO RADON FOR UNDERGROUND TOURIST ROUTES IN POLAND: DOSES TO LUNG AND THE RISK OF DEVELOPING LUNG CANCER"
}

Dear Editor,

We are writing with regard to the paper authored by Walczak et al. entitled "Occupational exposure to radon for underground tourist routes in Poland: Doses to lung and the risk of developing lung cancer" [1]. The authors of this paper evaluated the radon concentrations in 31 Polish underground tourist routes and calculated the equivalent dose to the lung. They also calculated the effective dose and the relative risk of lung cancer for the employees. The authors have reported that the relative risk of developing lung cancer for the people working in underground tourist routes was higher than for the general population. They have also reported that after 40 years of work, exposure to radon would be the cause of lung cancer in $42.3 \%$ of the cohort of all employees of the surveyed tourist routes. The authors used the Biological Effects of Ionizing Radiation (BEIR) VI Report [2] model for calculating the relative risk of developing lung cancer.

This paper has some major shortcomings. The first shortcoming comes from the assumed model which does not have supporting evidence. The BEIR VI report stated that based on the analysis of available residential radon studies, it could not determine the shape of dose-response and so it decided to utilize the linear no-threshold (LNT) model to estimate the lung cancer risk from residential radon. The report dismissed the ecological study of Cohen [3] (that showed the invalidity of the LNT model) by claiming that confounding by smoking can explain the reduction of lung cancers observed by Cohen with increasing radon levels. Such a criticism is not valid, and confounding by smoking cannot explain the observations, as described by Siegel et al. [4].

Since the time of the BEIR VI report, numerous studies have shown a negative correlation between lung cancer mortality and radon concentration. For example, the retrospective case-control study by Thompson et al. [5] showed substantial reduction of lung cancer rates between radon levels of $50 \mathrm{~Bq} / \mathrm{m}^{3}$ and $123 \mathrm{~Bq} / \mathrm{m}^{3}$ relative to a group at $0-25 \mathrm{~Bq} / \mathrm{m}^{3}$. Analogous findings were reported by other authors as described by Becker [6]. A recent study by Denton et al. has also shown reduction of lung cancers with increasing radon levels in Guam [7] whereas pooled studies [8,9] have claimed increased lung cancers with increasing residential radon levels, the Bayesian analysis of many of those studies [10] shows that the collection of published data does not support a conclusion 
that below $800 \mathrm{~Bq} / \mathrm{m}^{3}$ lung cancer risk increases with radon concentration. Furthermore, Scott's analysis of both residential and uranium miner data clearly shows that beneficial effects are observed for a broad range of radon concentrations [11].

In addition to the radon concentration, comparison of underground and aboveground radon dosimetry is complex and depends on a number of factors. The paper does not convincingly account for differences in occupancy factors, attached and unattached fractions, ambient dust size distributions, particle shape distributions, age distributions, concentrations of other inhaled materials, and ventilation characteristics that describe the underground and aboveground environments [12,13]. Although the Ramsar (Iran) factors noted below constitute the dominant consideration, these other factors must be addressed before drawing specific dosimetry conclusions.

One major problem with many radon studies is that they are very much under-powered, resulting in uncertain and contradictory conclusions. Another problem with many of the studies is that they have utilized the LNT model as an integral part of the analysis [4], and so are deeply flawed, since much evidence has accumulated against the LNT model over the years [14].

Additional evidence against the LNT model is provided by the study of populations who live in high background radiation areas (HBRAs) of Ramsar, the city which lies on the coast of the Caspian Sea. Residents of the HBRAs are exposed to indoor radon $\left({ }^{222} \mathrm{Rn}\right)$ levels up to $31000 \mathrm{~Bq} / \mathrm{m}^{3}$ [15], which is more than 200 times higher than the action level suggested for radon by the United States Environmental Protection Agency (US EPA) $\left(148 \mathrm{~Bq} / \mathrm{m}^{3}\right)$ [16]. Data obtained from the Ramsar health network has shown that age-adjusted lung cancer rates in the district with the highest recorded levels of radon concentration are lower than those of the other 7 districts [17].
It has, indeed, been standard practice to use measured radon data with the LNT model to estimate lung cancer risk, for example in the recent publication by Axelsson et al. [18]. Though it is standard practice, it is not correct because the LNT model is not supported by evidence.

In summary, the use of the LNT model to estimate lung cancer risk due to radon in this study is not justifiable. A proper model that takes into account the observed reduction of lung cancers in residential areas with higher radon levels should be utilized to estimate the lung cancer risk due to occupational exposure to radon for underground tourist routes in Poland.

\section{Key words: \\ Occupational exposure, Radon, Lung cancer, Risk, Poland, Underground routes}

\section{REFERENCES}

1. Walczak K, Olszewski J, Politański P, Zmyślony M. Occupational exposure to radon for underground tourist routes in Poland: Doses to lung and the risk of developing lung cancer. Int J Occup Med Environ Health. 2017;30(5):687-94, https:// doi.org/10.13075/ijomeh.1896.00987.

2. National Research Council (US) Committee on Health Risks of Exposure to Radon (BEIR VI). Health effects of exposure to radon: BEIR VI. Washington, D.C.: National Academies Press; 1999.

3. Cohen BL. Test of the linear-no threshold theory of radiation carcinogenesis for inhaled radon decay products. Health Phys. 1995;68(2):157-74, https://doi.org/10.1097/00004032-19 9502000-00002.

4. Siegel J, Pennington C, Sacks B, Welsh J. Rectifying radon's record: An open challenge to the EPA. Int J Radiol Imaging Technol. 2016;2(2):014, https://doi.org/10.23937/25723235.1510014 .

5. Thompson RE, Nelson DF, Popkin JH, Popkin Z. Case-control study of lung cancer risk from residential radon exposure in Worcester County, Massachusetts. Health Phys. 2008;94(3): 228-41, https://doi.org/10.1097/01.HP.0000288561.53790.5f. 
6. Becker K. Health effects of high radon environments in central Europe: Another test for the LNT hypothesis? Nonlinearity Biol Toxicol Med. 2003;1(1):3-35, https:/doi. org/10.1080/15401420390844447.

7. Denton GRW, Namazi S. Indoor radon levels and lung cancer incidence on Guam. Procedia Environ Sci. 2013;18:157-66, https://doi.org/10.1016/j.proenv.2013. 04.021 .

8. Krewski D, Lubin JH, Zielinski JM, Alavanja M, Catalan VS, Field RW, et al. A combined analysis of North American case-control studies of residential radon and lung cancer. J Toxicol Environ Health A. 2006;69(7):533-97, https://doi. org/10.1080/15287390500260945.

9. Darby S, Hill D, Auvinen A, Barros-Dios JM, Baysson H, Bochicchio F, et al. Radon in homes and risk of lung cancer: collaborative analysis of individual data from 13 European case-control studies. BMJ. 2005;330(7485):223, https://doi. org/10.1136/bmj.38308.477650.63.

10. Fornalski KW, Dobrzyński L. Pooled Bayesian analysis of twenty-eight studies on radon induced lung cancers. Health Phys. 2011;101(3):265-73, https://doi.org/10.1097/HP. 0b013e31821115bf.

11. Scott BR. Residential radon appears to prevent lung cancer. Dose Response. 2011;9(4):444-64, https://doi.org/10.2203/ dose-response.11-027.Scott.

12. Bevelacqua JJ. Contemporary health physics: Problems and solutions. 2nd ed. Weinheim: WILEY-VCH Verlag GmbH \& Co. KGaA; 2008.

13. Bevelacqua JJ. Basic health physics: Problems and solutions. 2nd ed. Weinheim: WILEY-VCH Verlag GmbH \& Co. KGaA; 2009.

14. Doss M. Evidence against the linear no-threshold hypothesis in the atomic bomb survivor cancer data and other data and reasons for a change in the radiation safety paradigm. In: Sutou S, Doss M, Tanooka H, editors. Fukushima nuclear accident: Global implications, long-term health effects, and ecological consequences. New York: Nova Science Publishers; 2015. p. 61-75.
15. Sohrabi M. World high background natural radiation areas: Need to protect public from radiation exposure. Radiat Meas. 2013;50:166-71, https://doi.org/10.1016/j.radmeas.2012.03.011.

16. George AC. The history, development and the present status of the radon measurement programme in the United States of America. Radiat Prot Dosimetry. 2015;167(1-3):8-14, https://doi.org/10.1093/rpd/ncv213.

17. Mortazavi SMJ, Ghiassi-Nejad M, Rezaiean M. Cancer risk due to exposure to high levels of natural radon in the inhabitants of Ramsar, Iran. Int Congr Ser. 2005;1276:436-7, https://doi.org/10.1016/j.ics.2004.12.012.

18. Axelsson G, Andersson EM, Barregard L. Lung cancer risk from radon exposure in dwellings in Sweden: How many cases can be prevented if radon levels are lowered? Cancer Causes Control. 2015;26(4):541-7, https://doi.org/10.1007/ s10552-015-0531-6.

S.M. Javad Mortazavi ${ }^{1}$, Joseph John Bevelacqua ${ }^{2}$, Krzysztof W. Fornalski ${ }^{3}$, Charles W. Pennington ${ }^{4}$, James Welsh ${ }^{5}$, Marek K. Janiak ${ }^{6}$, Ludwik Dobrzyński and Mohan Doss ${ }^{1}$

${ }^{1}$ Fox Chase Cancer Center, Philadelphia, USA Diagnostic Imaging ${ }^{2}$ Bevelacqua Resources, Richland, USA ${ }^{3}$ Ex-Polon Laboratory, Łazy, Poland

${ }^{4}$ NAC International, Retired; Nuclear Energy Consultant, Alpharetta, USA

${ }^{5}$ Loyola University, Chicago, USA Stritch School of Medicine, Department of Radiation Oncology

${ }^{6}$ Military Institute of Hygene and Epidemiology, Warszawa, Poland Department of Radiobiology and Radiation Protection

${ }^{7}$ National Centre for Nuclear Research, Otwock-Świerk, Poland Education and Training Division 
Corresponding authors:

Mohan Doss

Fox Chase Cancer Center

Diagnostic Imaging

333 Cottman Avenue

Philadelphia, PA 19111-2497, USA

(e-mail: Mohan.Doss@fccc.edu)

Ludwik Dobrzyński

National Centre for Nuclear Research

Education and Training Division

ul. Andrzeja Sołtana 7, 05-400 Otwock-Świerk, Poland

(e-mail: ludwik.dobrzynski@ncbj.gov.pl)

This work is available in Open Access model and licensed under a Creative Commons Attribution-NonCommercial 3.0 Poland License - http://creativecommons.org/ licenses/by-nc/3.0/pl/deed.en. 